\title{
Considerações sobre o Gasto em Saúde no Brasil: Dilemas até o Final do Século*
}

\author{
Pedro Luiz Barros Silva \\ Andre Cezar Medici
}

\section{1 - INTRODUÇÃO}

A crise da economia brasileira,compreendida entre 1980 e 1984, associada à brilhante e efêmera recuperação do período 1985 e 1986,coloca de forma evidente aos analistas as distorções e limitações da precária e desigual engrenagem de promoção de políticas sociais e de constituição de uma socieđade mais homogênea no Brasil. A rápida recuperação vivida desde setembro de 1984 e acelerada com o advento do plano de estabilização econômica,a partir de fevereiro de 1986, demanstrou ser possivel viabilizar o sonho de construir uma sociedade capitalista retardatária que seja economicamente pujante e socialmente mais redistributiva.

Os impactos desta recuperação nos mecanismos de fornecimento de bens e serviços de corte social, especialmente na área da saúde, só não foram maiores em decorrência da fragilidade operacional dos sistemas de prestaçāo, deteriorados pela prática de utilizaçāo dos recursos e da máquina burocrática do setor, ao longo dos governos autoritários.

Apesar do estímulo trazido ao setor saúde nesses anos de crescimento no volume de recursos gastos, a perspectiva de crise efetivamente inaugurada em 1987 nos coloca em um grave dilema: não basta gastar espasmodicamente nos setores sociais. $\dot{E}$ necessário fazer inversōes e reordenamentos profundos na máquina burocrática dos setores sociais que sejam capazes de dar continuidade, de forma complementar, a uma política econômica que garanta a construção de uma sociedade mais equânime nos frutos de seu desenvolvimento. Isto requer a estruturação de fontes de financiamento compatíveis com a complexidade dada pelos limites do crescimento e com as metas de redistribuição e universalização que se almeja alcançar.

Os limites do crescimento estão dados pelas variáveis macroeconômicas, pelo ajustamento interno e pelo ajustamen. to externo em face das perspectivas dadas pela dinâmica da economia internacional. As metas de redistribuição e universalização, no caso do setor saúde, envolvem a constru-

* Os autores agradecem as insti. gantes observações e comentários de José Carvalho de Noronha, que auxiliaram o desenvolvimento des. te ensaio. çāo de um sistema unificado e descentralizado que proporcione, à totalidade da população brasileira, um atendimento in tegral, regionalizado e hierarquizado e com capacidade resolutiva.

Cadernos de Saúde Pública, RJ, 1(4): 88-105, jan/mar, 1988 
Tal desafio requer, não só recursos maiores e estáveis fontes de financiamento, como também sua correta distribuição intergovernamental, o que depende da direcionalidade e eficácia do processo de reforma tributária em dois sentidos:

a) maior comprometimento do gasto fiscal com as políticas sociais;

b) sua adequada redistribuição entre as esferas de governo de modo a possibilitar que cada uma delas possa suportar o gasto com aquela parcela do sistema de atendimento sob sua jurisdição.

O obje tivo desse ensaio é, partindo da análise do comportamento das fontes de financiamento do setor saúde e dos montantes de gasto permitidos por cada uma, construir cenários alternativos, a partir da discussão de algumas hipóteses de crescimento dos recursos captados e suas possiveis aplicações.

\section{2 - FONTES DE FINANCIAMENTO E DIMENSÕES DO GASTO EM SAÚDE}

\section{1 - Síntese das Fontes}

Os mecanismos de financiamento da intervenção estatal em atenção à saúde podem ser divididos em três grandes blocos:

a) No primeiro bloco, o financiamento é efetuado atra. vés da destinação dos recursos originários do orçamento fis. cal, os quais têm sido aplicados prioritariamente no desenvolvimento das ações em atenção médica sanitária e correlatas (serviços básicos de saúde, controle de doenças transmissíveis, produtos profiláticos e terapêticos, alimentação e nutrição). Além disso algumas ações no campo médicohospitalar são financiadas com recursos do orçamento fiscal, destacando-se a manutenção dos hospitais do Ministério da Saúde, do MEC e dos Ministérios Militares.

b) No segundo bloco, os recursos provêm dos mecanismos de financiamento do SINPAS, isto é, das contribuições compulsórias de empregados, empregadores e das contribuições da União. Estas últimas são destinadas a cobrir, em tese, as despesas de custeio e eventuais insuficiências do SINPAS. Tais recursos estão voltados, de modo, geral ao financiamento das ações de natureza médico-hospitalar para a clientela do complexo médico-previdenciário.

c) No terceiro bloco, os recursos provêm, em parte, do orçamento fiscal e de outra parte, das receitas tributárias próprias dos Estados e Municípios. Destinam-se a financiar as ações das Secretarias Estaduais e Municipais de saúde, ligadas a manutenção de postos e centros de saúde, voltados 
à atenção primária para as populações locais. São utiliza. dos, também, na manutenção dos hospitais gerais, estaduais e municipais, onde funcionam serviços clínicos e cirúrgicos bem como atendimentos de emergência com maior complexidade.

Ainda que a separação desses três blocos venha, nos anos mais recentes, se tornando menos clara, em virtide da participação de recursos previdenciários em programas financia. dos de forma usual pelo orçamento fiscal, bem como, pela transferência de recursos do SINPAS às secre tarias de saúde estaduais e municipais, através das Ações Integradas de Saúde, vale configurar, neste trabalho, a existência de três mecanismos de financiamento bem distintos. Ao examinar sua natureza, pretende-se aferir os padrões prevalescentes de financiamento do desenvolvimento social no Brasil.

Deve-se admitir, ainda, a existência de um quarto bloco de recursos oriundos de fundos sociais extra-orçamentários, tais como o FINSOCIAL, FGTS, PIS/PASEP, Salário-Educação, PIN/PROTERRA, FAS e Contribuição Sindical. Esses recursos, se somados à receita previdenciária, constituiriam $83 \%$ da receita tributária da União em 1984, configurando, praticamente, um segundo Orçamento Fiscal. As transferências desses fundos para o setor saúde têm sido cada vez mais elevadas.

\section{2 - O Gasto Federal em Saúde.}

O gasto federal em saúde compreende, como vimos, a soma dos recursos do Tesouro, recursos do FPAS e de recursos dos Fundos Sociais, em especial o FAS e o FINSOCIAL, e de outras fontes cuja importância vem declinando continuadamente nos anos oitenta.

A tabela 1 evidencia que entre 1980 e 1986, o gasto da Previdência Social continua sendo a principal fonte de cus. teio das políticas de saúde. Com exceção de 1984, sua participação no gasto tal vem declinando, passando de $85,7 \%$ no início da década a 77\%, aproximadamente, em 1986. Essa diminuição relativa pode ser atribuída, ao aumento da participação dos gastos federais, que evoluíram de $13 \%$ (em 1980) para quase $23 \%$ (em 1986) num processo contínuo de aumento real de recursos, à exceção dos anos de 1983 e 1984 . O mesmo não se pode dizer em relação aos recursos da Previdência Social, onde observou-se uma queda real de $27 \%$ entre 1980 e 1983 . A recuperação do nível de gastos ocorrida de 1984 a 1986 não foi suficiente, todavia, para recuperar o patamar atingido no início da década. Isso é agravado pelo fato da população brasileira, em igual período, ter crescido significativamente, passando de 119 milhões de habitantes, em 1980, para algo em torno de 139 milhões em 1986. 
TEMA

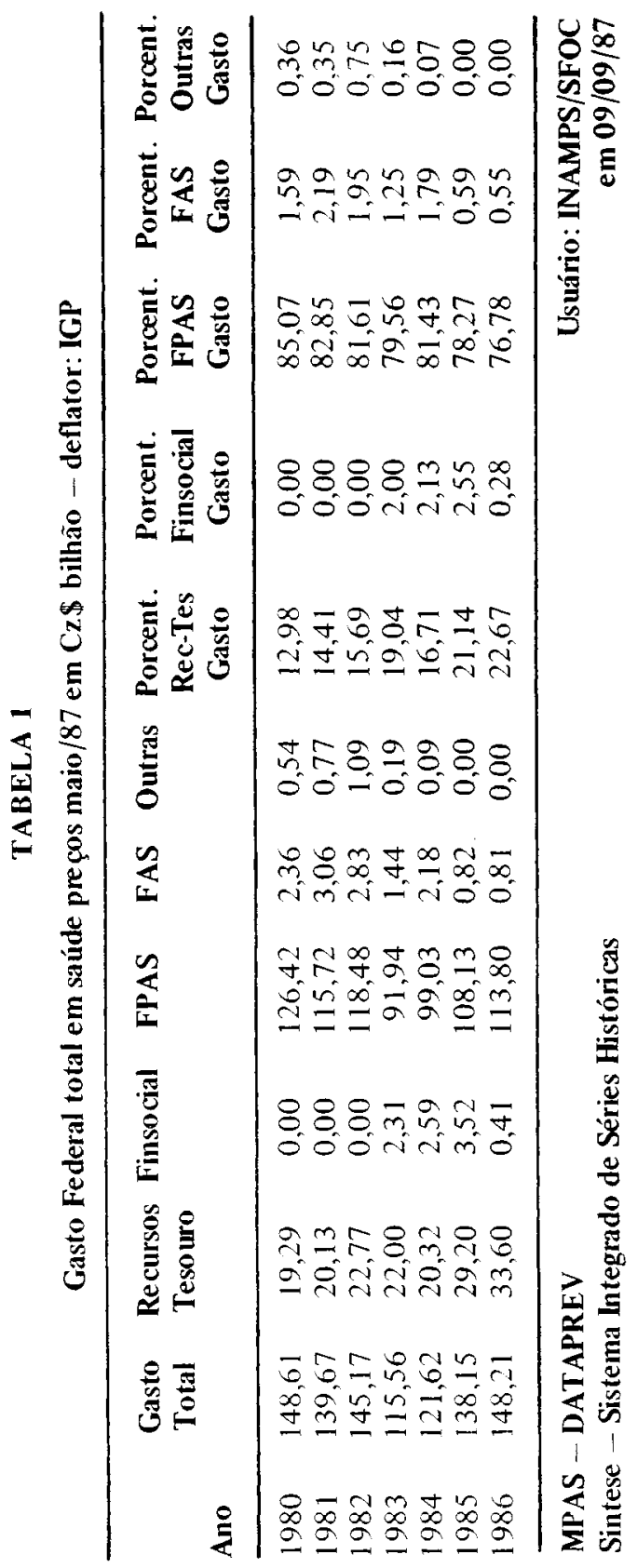


Cabe ressaltar que os Fundos Sociais, em especial o FAS, e FINSOCIAL detêm participação reduzida no financiamento do investimento, pois nota-se que o somatório dos recursos despendidos por esses fundos, em nenhum momento ultrapassou os $4 \%$ do total de gasto federal em Saúde, quan. tia irrisória para qualquer esforço consistente de recuperação da base técnica instalada no se tor público.

O somatório de todos esses itens evidencia que o gasto federal em saúde realizado em $1986 \mathrm{da}$ ordem de C $2 \$ \ldots$ 148,2 bilhões a preços de maio de 1987, situando-se ain da um pouco abaixo dos recursos despendidos ao setor em 1980. Isto porque de 1980 a 1983 , o gasto global reduziu-se para $\mathrm{C} z \$ 115,6$ bilhões (decréscimo de $22,2 \%$ ) só voltando a se recuperar em 1984 conjuntamente com a retomada do crescimento da economia, do emprego e dos salários.

Em decorrência, o gasto federal per capita em saúde, como demonstra a tabela 2 , é irrisório, não chegando, sequer a meio salário mínimo anual por habitante (Cz\$ 1.066,00 em 1986, a preços de maio de 1987).

TABELA 2

Gasto Federal per capita em saúde a preços maio/87

\begin{tabular}{lcccccc}
\hline & $\begin{array}{c}\text { Gasto } \\
\text { Total } \\
\text { Pno }\end{array}$ & $\begin{array}{c}\text { Recurso } \\
\text { Tesouro } \\
\text { Per capita }\end{array}$ & $\begin{array}{c}\text { Finsocial } \\
\text { Per capita }\end{array}$ & $\begin{array}{c}\text { FPAS } \\
\text { Per capita }\end{array}$ & $\begin{array}{c}\text { FAS } \\
\text { Per capita }\end{array}$ & $\begin{array}{c}\text { Outras } \\
\text { Per capita }\end{array}$ \\
\hline 1980 & $1.248,80$ & 162,10 & 0,00 & $1.062,33$ & 19,83 & 4,54 \\
1981 & $1.126,23 \mathrm{E}$ & $162,32 \mathrm{E}$ & - & $993,11 \mathrm{E}$ & $24,67 \mathrm{E}$ & $6,21 \mathrm{E}$ \\
1982 & $1.144,82 \mathrm{E}$ & $179,57 \mathrm{E}$ & - & $934,34 \mathrm{E}$ & $22,32 \mathrm{E}$ & $8,60 \mathrm{E}$ \\
1983 & $891,25 \mathrm{E}$ & $169,67 \mathrm{E}$ & $17,82 \mathrm{E}$ & $709,09 \mathrm{E}$ & $11,11 \mathrm{E}$ & $1,47 \mathrm{E}$ \\
1984 & $917,33 \mathrm{E}$ & $153,27 \mathrm{E}$ & $19,54 \mathrm{E}$ & $746,95 \mathrm{E}$ & $16,44 \mathrm{E}$ & $0,68 \mathrm{E}$ \\
1985 & $1.019,08 \mathrm{E}$ & $215,40 \mathrm{E}$ & $25,97 \mathrm{E}$ & $797,63 \mathrm{E}$ & $6,05 \mathrm{E}$ & - \\
1986 & $1.066,26 \mathrm{E}$ & $241,73 \mathrm{E}$ & $2,95 \mathrm{E}$ & $818,71 \mathrm{E}$ & $5,83 \mathrm{E}$ & - \\
\hline
\end{tabular}

MPAS -- DATAPREV

Sintese - Sistema Integrado de Séries Históricas

Cz\$ - Deflator: IGP

Usuário: INAMPS/SFOC

em 09/09/87

\subsection{O Gasto Público em Saúde das Administrações Estaduais e Municipais}

Os gastos com saúde realizados pelos Estados e Municipios montavam recursos da ordem de US\$ 1,9 bilhão em 1984. Estimativas para 1986, conforme mostra a tabela 3, 
evidenciam uma elevação real desse gasto para US $\$ 2,2$ bilhões ( $14 \%$ no período), o que equivale a cerca de $\mathrm{Cz} \$$. . . . 65,0 bilhões, se forem eliminados duplas contagens e possiveis erros de estimava. Tal dispêndio equivale a metade dos gastos do INAMPS e pouco mais de $1 / 3$ dos gastos públicos federais com saúde, refletindo o processo de centralização de recursos que ainda perdura em nosso país. Países próxi. mos, como a Argentina, detêm relações bem mais descentralizadas, onde o gasto das províncias e municipalidades, equivale a mais de $2 / 3$ do gasto federal.

TABELA 3

Estimativa do gasto Estadual e Municipal

Com Programas Sociais. Brasil 1984 - 1986

(Em US\$ milhões de 1984)

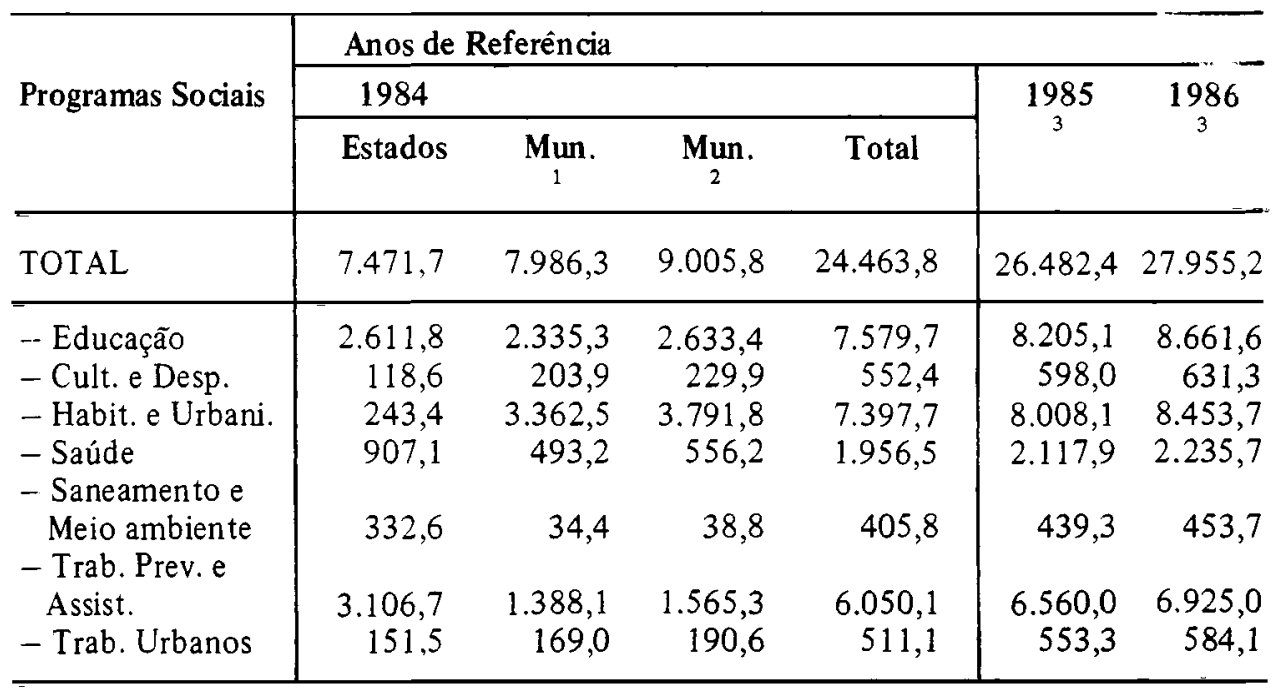

IONTE: IBGE/DEASP

1 Municipios pesquisados: Capitais Estaduais e Regiōes Metropolitanas

2 Estimativa para os demais municipios

${ }^{3}$ Estimativa pela taxa de crescimento do PIB

Elaboraçāo: André Medici

No caso brasileiro, o padrão de distribuição de recursos para a saúde entre as esferas de Governo implica numa completa dependência dos níveis locais e regionais às fontes de financiamento e aos perfis de política desenhados pelo Governo Federal. Ao mesmo tempo, os Estados e Municípios gestaram internamente um padrão de gastos onde a ausência de preocupação com o resultado final dos serviços implicou, 
como mostra a tabela 4, em grandes distorções, ou seja: altos percentuais de gasto com atividades burocráticas e alocação deficiente de recursos nos programas de assistência sanitária geral, que se constituem tarefas precípuas destas esferas de Governo.

Tais evidências mostram que, não só é preciso reverter este nivel de centralização como reordenar o padrão do gasto em saúde realizado pelos Estados e Municípios.

\section{TABELA 4 \\ Distribuição dos Gastos Estaduais e \\ Municipais Consolidados com os \\ Subprogramas de Saúde \\ Brasil 1984 \\ (US\$ milhões)}

\begin{tabular}{|c|c|c|c|c|}
\hline \multirow[b]{2}{*}{$\begin{array}{l}\text { Subprogramas } \\
\text { de Saúde }\end{array}$} & \multirow[b]{2}{*}{$\underset{2}{\text { Estados }}$} & \multicolumn{3}{|c|}{ Gastos $^{1}$} \\
\hline & & $\underset{2}{\text { Municípios }}$ & $\begin{array}{l}\text { Total } \\
\text { ABS }\end{array}$ & $\%$ \\
\hline TOTAL & 915,5 & 493,8 & $1.408,9$ & 100,0 \\
\hline $\begin{array}{l}\text { Administração } \\
\text { Ass. Sanitária }\end{array}$ & 246,4 & 59,0 & 305,4 & 21,7 \\
\hline $\begin{array}{l}\text { Geral } \\
\text { Ass. Hospitalar }\end{array}$ & 202,0 & 326,3 & 528,3 & 37,5 \\
\hline $\begin{array}{l}\text { Geral } \\
\text { Nutrição e }\end{array}$ & 409,1 & 106,0 & 515,1 & 36,6 \\
\hline $\begin{array}{l}\text { Alimentação } \\
\text { Estudo e Pesq. na } \\
\text { área biológica e } \\
\text { saúde }\end{array}$ & 17,7 & 2,5 & 20,2 & 1,4 \\
\hline \multicolumn{5}{|c|}{$\begin{array}{l}\text { FONTE: IBGE } / D E A \overline{A P} \\
1 \text { Inclui Transferências Intergovernamentais } \\
{ }^{2} \text { Municipios das Capitais Estaduais e Regiäo Metropolitana }\end{array}$} \\
\hline
\end{tabular}

\subsection{O Gasto Global em Saúde}

Embora não existam informações precisas e sistemáticas sobre a magnitude do gasto total em saúde, dada a ausência de informações sobre o gasto privado, estima-se que este, em 1982, situava-se na ordem de $38 \%$ em relação ao gasto total realizado. As pessoas físicas eram responsáveis por $26 \%$, os sistemas patronais $5 \%$, o gasto em seguro saúde $4 \%$ e os sistemas sindicais e entidades filantrópicas 3\%. Dados da Receita Federal indicam que os abatimentos, com médicos, dentistas, psicólogos e serviços hospitalares montavam, 
em 1984, a US\$ 620 milhões. Tal cifra representava, à época, $18 \%$ do gasto federal em saúde e aproximadamente $23 \%$ sobre o gasto realizado pelo INAMPS. Note-se que essa quantia já foi maior no passado, chegando a aproximarse da casa dos $40 \%$ do total de gastos do INAMPS no início da década. É possível supor que essa (40\% do total gasto pelo INAMPS) cifra seja um bom indicador do gasto declarado pelas pessoas físicas em 1986.

Supondo-se que em 1986 a distribuição in terna do gasto privado com saúde manteve-se, no essencial, idêntica e equivalente aos $38 \%$ do gasto global, estima-se que tais gastos podem ter chegado a 130 bilhões de cruzados naquele ano. Isto faria com que o gasto global com saúde chegasse a 343,2 bilhões de cruzados, ou seja US\$ 10 bilhões ou ainda cerca de $3,9 \%$ do PIB. Isto equivaleria a um gasto global de $C z \$ 2.469,00$ anuais per capita. Se considerarmos que o gasto privado envolve, no máximo 15 milhões de pessoas, isso significa um gasto anual per capita na área privada de Cz\$ 8.667,00 para este segundo, o qual envolve, reconhecidamente, a população com maior poder aquisitivo.

$O$ gasto per capita da imensa maioria da população, segundo esse raciocínio, se reduz a $\mathrm{Cz} \$ 1.719,00$, em termos anuais, demonstrado, além da ineqüidade, a insuficiência do volume de recursos despêndidos no Brasil com atenção a saúde. Na Argentina, por exemplo, gasta-se $\mathrm{Cz} \$ 6.300,00$ anuais per capita com saúde, com uma distribuição da des. pesa sabidamente mais equânime.

\section{3 - A ESTRUTURA INTERNA DO GASTO DO INAMPS NO PERIOODO RECENTE}

O gasto do INAMPS, conforme demonstra a tabela 5 , tem oscilado de 1979 a 1986 de 22\% (1983) ao máximo de $27,6 \%$ em 1980, da despesa total realizada pelo MPAS em todas as suas funções. Como não há uma fixação "a priori" dos recursos destinados a saúde, os gastos do INAMPS detêm caráter residual em relação a despesa realizada com beneficios e conjunturalmente têm-se retraído nos períodos recessivos, de acordo com a mesma tabela. Em termos reais isso significou um decréscimo de $25 \%$ na conjuntura mais crítica (25\% entre 1980 e 1983) e, apesar da elevação ocorrida a partir de 1984 , não se conseguiu recuperar o nivel de gastos realizados em 1980 por aquela instituição.

A distribuição da despesa do INAMPS por prestadores (tabelas 6 e 7) revela uma rápida modificação na composição interna do gasto, a partir de 1984 , notadamente no que diz respeito a distribuição dos recursos entre os setores público/privado. Até 1983 , o setor privado contratado detinha uma participação superior a $61 \%$ da despesa realizada. Note-se que entre 1979 e 1980 , tal participação era superior 
a $75 \%$. Em 1985 e 1986 ela se reduz para $49 \%$ e $46 \%$ respectivamente. Com isso, passam a ser privilegiados a rede própria de serviços do INAMPS e os convênios realizados com órgãos governamentais (Estados e Municípios) e com as Universidades. Trata-se de um esforço pioneiro de conseguir produzir serviços de saúde utilizando mais adequadamente a capacidade instalada do setor público. Dado o caráter recente dessa diretriz, que se inicia com as Açōes Integradas de Saúde e se intensifica com a recente experiência de implantação do sistema unificado e descentralizado, é preciso ter claro que um esforço efetivo de obter melhor desempenho de uma rede de serviços tão deteriorada tem limites reais que são a própria capacidade de investimento no setor e a manutenção e mesmo ampliação dos gastos em custeio observados no período recente. Somente um esforço no sentido de ampliar tal capacidade de investimento e custeio, associada a uma correta organização dos sistemas estaduais e locais de saúde poderá garantir uma efetiva transformação da política de saúde de forma a aumentar a qualidade e a quantidade de serviços, à disposição dos usuários, num sistema mais equânime, integrado e universal.

E importante destacar, finalmente, que a complexidade e a heterogeneidade da sociedade brasileira associadas a uma rápida transformação do padrão epidemiológico, vinculadas ao aumento dos niveis de urbanização e metropolização, impõem, ao contrário do que se pensava no final dos anos se. tenta, a manutenção de uma política que, a despeito de ampliar os cuidados em saúde nos níveis de atendimento primário e secundário, garanta o contínuo desenvolvimento dos niveis de maior complexidade. Sem isso, será impossi. vel enfrentar os problemas de saúde de uma nação onde coexistem as doenças da pobreza e as mazelas das sociedades pós-industriais.

\section{4 - CENÁRIOS ALTERNATIVOS DE CRESCIMENTO DOS GASTOS EM SAÜDE DO INAMPS.}

A tarefa de projeção dos niveis de gastos em políticas sociais, numa sociedade onde a questão redistributiva não se encontra suficientemente equacionada, e a vontade política dos governantes em obtê-la é oscilante na prática e normativa no planejamento, é sem dúvida uma aventura. Neste ensaio, preferimos fugir da árdua tarefa de combinar, no plano econométrico, variáveis de desempenho da economia (crescimento do produto, multiplicador emprego/salários, evolução da carga tributária, impacto sobre a arrecadação previdenciária, comportamento da inflação e balanço de pagamentos) e demanda por bens c serviços públicos de naturcza social, para conseguir determinar algumas projeçōes. 
TEMA

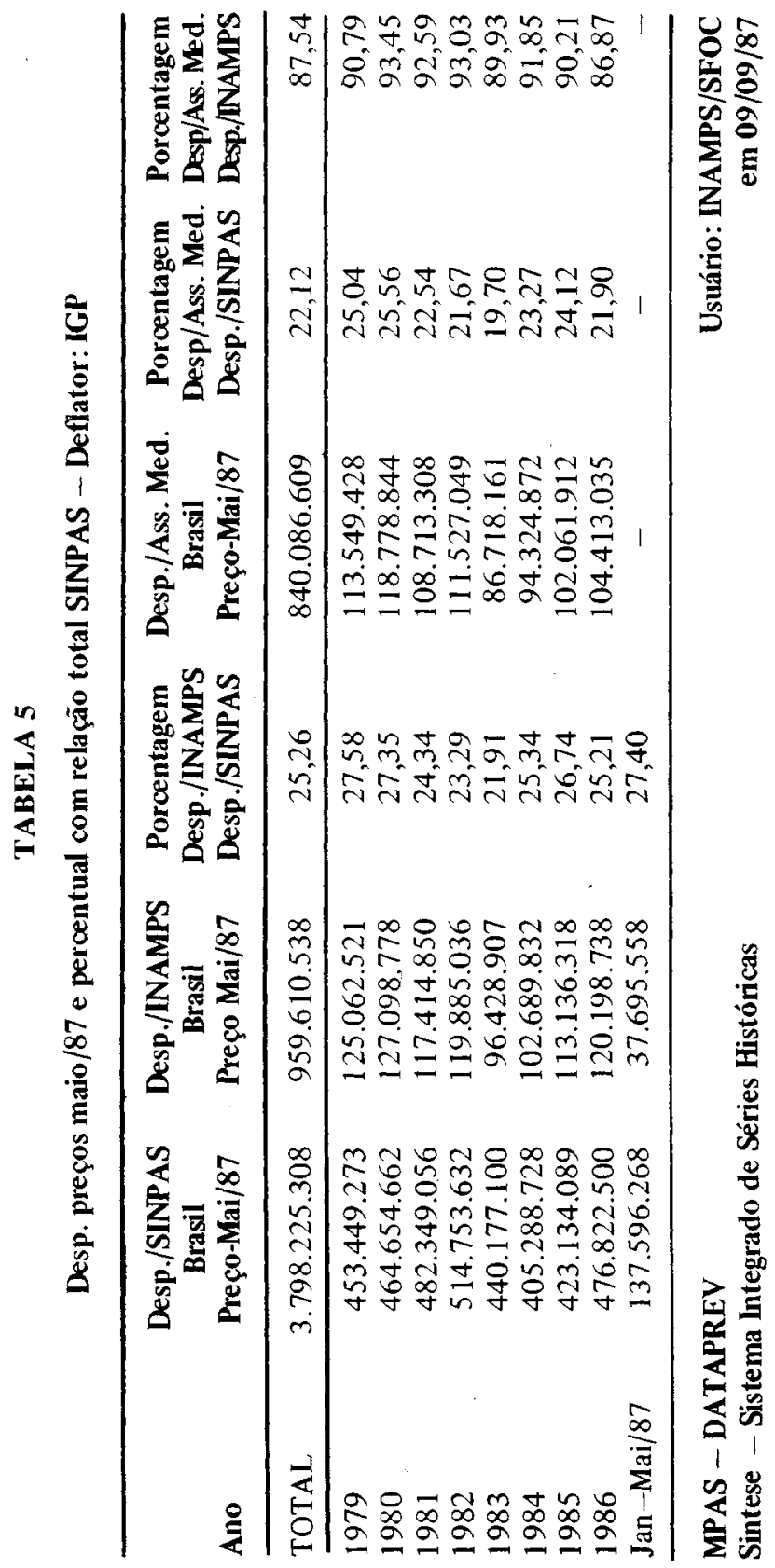




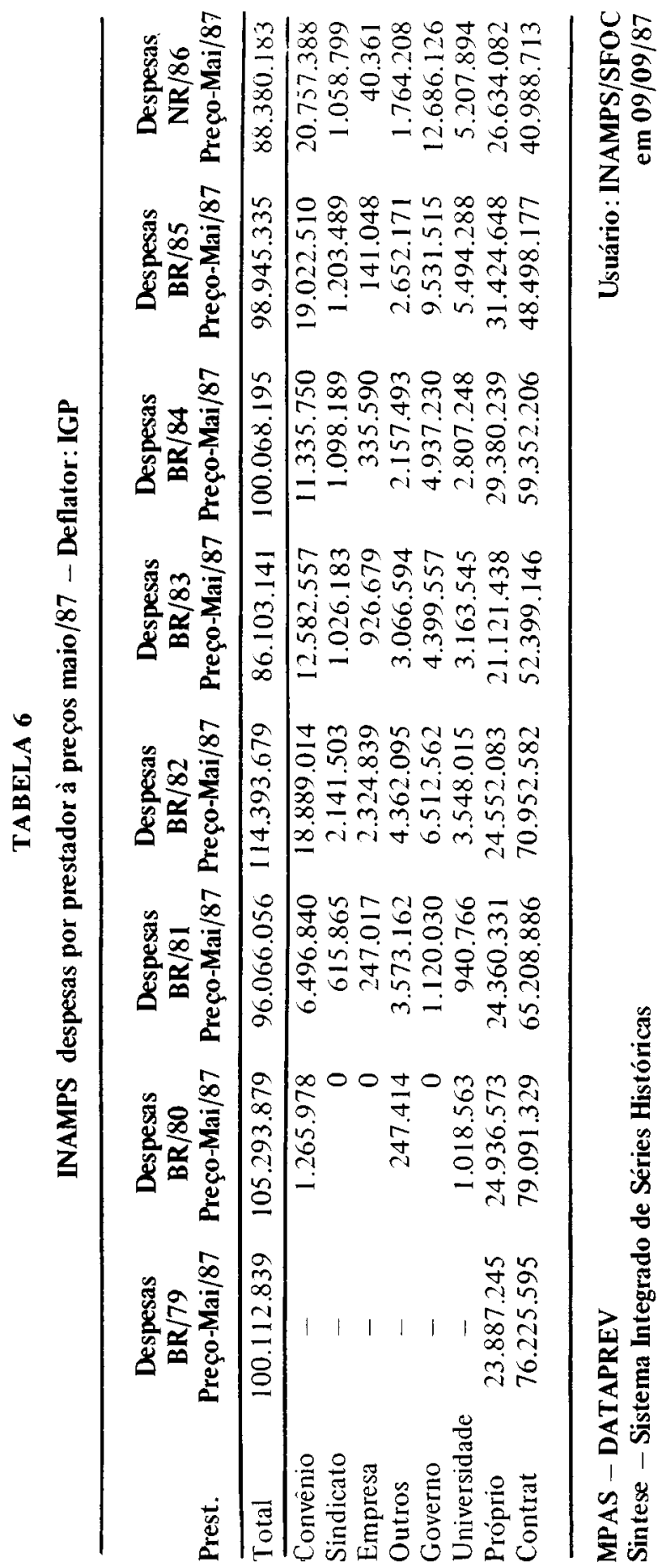




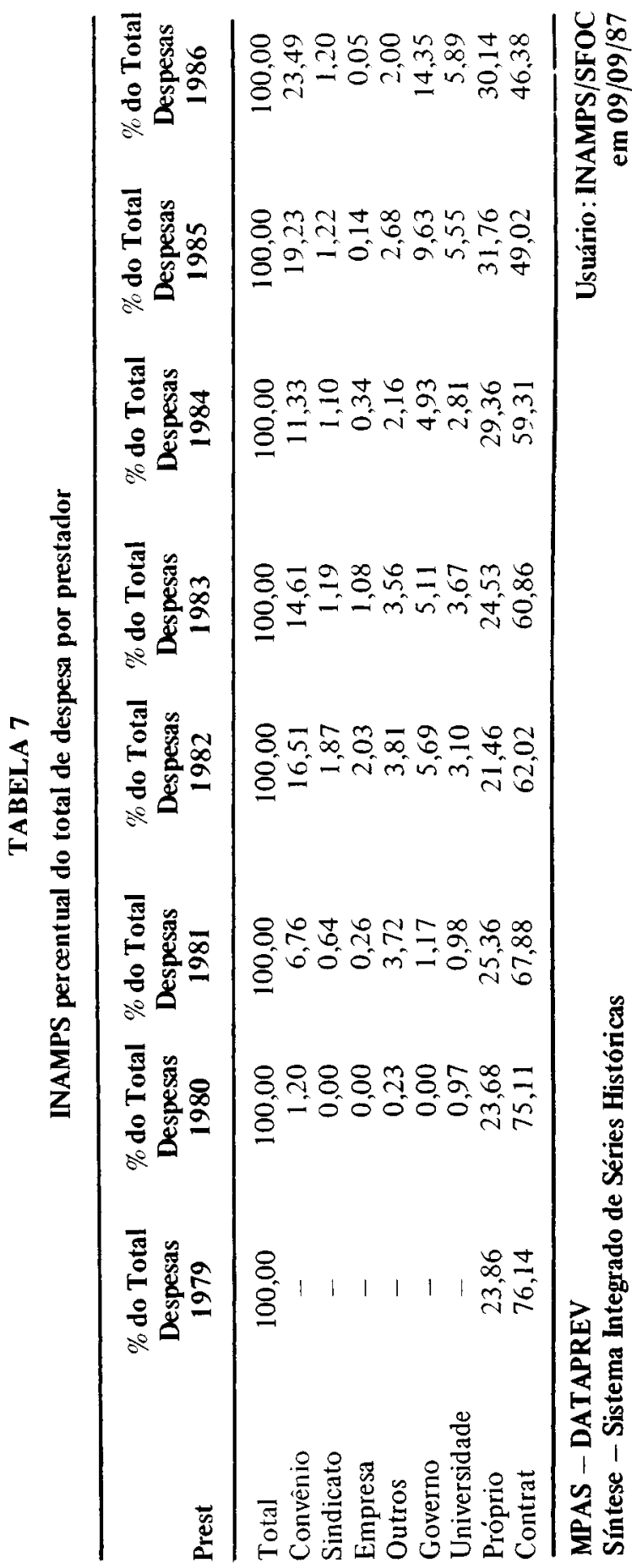


Preferimos construir cenários alternativos a partir de alguns comportamentos possiveis e razoáveis das únicas variáveis que nos parecem controláveis ou seja, o comportamento da arrecadação das contribuições compulsórias da Previdência Social, da receita total do SINPAS e do gasto do INAMPS. Tal escolha prende-se a duas ordens de fatores:

a) Trata-se de um conjunto de variáveis associadas ou dependentes de um fundo de financiamento que se constitui legal e historicamente um patrimônio dos trabalhadores e da própria sociedade brasileira, sofrendo por isso, em grau menor, o arbítrio dos governantes. Isso significa que tal fundo possui um grau de autonomia relativa de suas aplicações, tal fato tem garantido uma certa continuidade de fluxos; o que não significa desde logo que defenda-se aqui o seu grau de predominâncias no financiamento das ações de saúde.

b) Como o INAMPS representa a maior parcela do gasto federal em saúde no Brasil, podemos formular hipóteses sobre os niveis de gasto futuro desta instituição e derivar daí a necessidade de gasto das outras esferas de Governo para que possamos atingir patamares compativeis com a complexidade do perfil de saúde da população nos próximos anos, ainda que de maneira simplificada.

Nossa hipótese básica parte de três cenários alternativos. 0 primeiro, denominado "cenário de estabilidade (quadro em anexo)" pressupõe que a despesa do INAMPS equivaleria a 27\% da receita do SINPAS em 1988; 28\% em 1989 e 30\% de 1990 até o ano 2000 . O patamar de $30 \%$ não é um número mágico, mas sim a observação, com algum otimismo, de um nivel razoável de participação da Previdencia Social no gasto em saúde, dada a limitação imposta pelo movi. mento real de arrecadação e de despesas com benefícios. A receita total foi estimada anualmente sendo $5 \%$ superior à arrecadação, para fins de simplificação.

$\mathrm{O}$ crescimento da arrecadação neste cenário é nulo em 1987 e 1988, em termos reais, em função das possíveis estratégias de ajuste da economia brasileira. A partir de 1989 supõe-se um crescimento de $1,26 \%$ reais ao ano, o que seria suficiente para compensar o crescimento dos empregos e dos salários em patamares bem módicos e com a manutenção de um patamar de desemprego superior ao friccional.

Neste cenário as despesas do INAMPS no ano 2000, a preços de maio de 1987 , chegarão a 178,5 bilhões de cruzados com um crescimento bruto estimado em $37 \%$ entre 1987 e 2000.

O segundo cenário, pessimista, tem como hipóteses básicas um decréscimo de arrecadação de $2 \%$ reais em 1987 e 1988 e um crescimento entre 1989 e 2000 da ordem de $0,74 \%$ ao ano. Nesta hipótese a economia brasileira perma- 
neceria com fortes restrições tanto internas quanto externas ao crescimento e o multiplicador emprego/salário cresceria muito menos do que a oferta global de força de trabalho, resultanjo, ou numa deterioração do salário real (caso a absorção de emprego, seja maior) ou num aumento do desemprego (ca, os salários permaneçam constantes ou aumentem ligeiramente).

\section{Cenários Altemativos de Crescimento do Gasto do SINPAS}

\begin{tabular}{|c|c|c|c|}
\hline \multirow[b]{2}{*}{ Ano } & \multirow[b]{2}{*}{$\begin{array}{l}\text { Arrecadação } \\
\text { Contribuição } \\
\text { Compulsória }\end{array}$} & \multicolumn{2}{|c|}{ Cenário de Estabilidade } \\
\hline & & $\begin{array}{c}\text { Receita } \\
\text { Total } \\
\text { SINPAS }\end{array}$ & $\begin{array}{c}\text { Despesa } \\
\text { Ass. Médica } \\
\text { INAMPS }\end{array}$ \\
\hline 1983 & 405.9 & 432.5 & 96. \\
\hline 1984 & 34.341 & 403.9 & 102. \\
\hline 1985 & 398.858 .619 & 439.420 .940 & 113.224 .675 \\
\hline 1986 & 491.956 .373 & 509.642 & 120.097 .965 \\
\hline 1987 & 487.649 .297 & 555.600 .000 & 130.141 .494 \\
\hline 1988 & 487.649 .297 & 512.031 .762 & 138.248 .576 \\
\hline 1989 & 93.678 & 51 & 145.175 .341 \\
\hline 1990 & 500.015 .478 & 525.016 .252 & 157.504 .876 \\
\hline 1991 & 506.315 .673 & 531.631 .457 & 159.489 .437 \\
\hline 1992 & 512.695 .251 & & 161.499 .004 \\
\hline 1993 & 519.155 .211 & 545.112 .972 & 163.533 .892 \\
\hline 1994 & 525.696 .567 & 551.981 .395 & 165.594 .419 \\
\hline 1995 & .344 & 55 & 167.680 .908 \\
\hline 1996 & 539.027 .580 & 565.978 .959 & 169.793 .688 \\
\hline 1997 & 545.819 .327 & 573.110 .294 & 171.933 .088 \\
\hline 1998 & 552.696 .651 & 580.331 .483 & 174.099 .445 \\
\hline 1999 & 559.660 .629 & 587.643 .660 & 176.293 .098 \\
\hline 2000 & 566.712 .353 & 595.047 .970 & 178.514 .391 \\
\hline$O b$ & \multicolumn{3}{|c|}{$\begin{array}{l}\text { 1) Crescimento arrecadaçāo } 87-88=0 \% \\
\text { 2) Crescimento arrecadação } 1988-2000=1,26 \% \\
\text { 3) Receita total } 5 \% \text { maior que a arrecadada } \\
\text { 4) Despesa do INAMPS equivalente a } 27 \% \text { receita em } \\
198828 \% \text { em } 1989 \text { e } 30 \% \text { até } 2000 \\
\text { 5) Valores a precos maio } / 87 \text { - deflator:IGP } \\
\text { 6) Valores em CZ } \$ \text { mil } \\
\text { SINTESE IDATAPREV }\end{array}$} \\
\hline
\end{tabular}

Elaboração: Redro Luiz B. Silva e André Medici.

Mantêm-se as mesmas hipóteses para o nivel de participa. ção do INAMPS na receita total e dos critérios de formação desta receita. Neste caso as despesas do INAMPS no ano 2000 chegariam a 164,5 bilhões de cruzados, com um crescimento bruto estimado em apenas $26,5 \%$ com relação a 1987. 


\section{Cenários Alternativos de Crescimento do Gasto do SINPAS}

Cenário Pessimista

\begin{tabular}{|c|c|c|c|}
\hline Ano & $\begin{array}{l}\text { Arrecada çâo } \\
\text { Contrib uição } \\
\text { Compulsória }\end{array}$ & $\begin{array}{l}\text { Receita } \\
\text { Total } \\
\text { SINPAS }\end{array}$ & $\begin{array}{c}\text { Despesa } \\
\text { Ass. Médica } \\
\text { INAMPS }\end{array}$ \\
\hline 1983 & 405.935 .495 & 432.566 .675 & 96.423 .036 \\
\hline 1984 & 354.134 .341 & 403.994 .193 & 102.681 .330 \\
\hline 1985 & 398.858 .619 & 439.420 .940 & 113.224 .675 \\
\hline 1986 & 491.956 .373 & 509.642 .530 & 120.097 .965 \\
\hline 1987 & 487.649 .297 & 555.600 .000 & 130.141 .494 \\
\hline 1988 & 477.896 .311 & 501.791 .127 & 135.483 .604 \\
\hline 1989 & 481.432 .744 & 505.504 .381 & 141.541 .227 \\
\hline 1990 & 484.995 .346 & 509.245 .113 & 152.773 .534 \\
\hline 1991 & 488.584 .312 & 513.013 .527 & 153.904 .058 \\
\hline 1992 & 492.199 .835 & 516.809 .827 & 155.042 .948 \\
\hline 1993 & 495.842 .114 & 520.634 .220 & 156.190 .266 \\
\hline 1994 & 499.511 .346 & 524.486 .913 & 157.346 .074 \\
\hline 1995 & 503.207 .730 & 528.368 .116 & 158.510 .435 \\
\hline 1996 & 506.931 .467 & 532.278 .040 & 159.683 .412 \\
\hline 1997 & 510.682 .760 & 536.216 .898 & 160.865 .069 \\
\hline 1998 & 514.461 .812 & 540.184 .903 & 162.055 .471 \\
\hline 1999 & 518.268 .830 & 544.182 .271 & 163.254 .681 \\
\hline 2000 & 522.104 .019 & 548.209 .220 & 164.462 .766 \\
\hline Obs: & \multicolumn{3}{|c|}{$\begin{array}{l}\text { 1) Crescimento arrecadaçāo } 87-88=-2 \% \\
\text { 2) Crescimento arrecadação } 1988-2000=0.74 \% \\
\text { 3) Receito total } 5 \% \text { maior que a arrecadada } \\
\text { 4) Despesa do INAMPS equivalente a } 27 \% \text { receita em } \\
198828 \% \text { em } 1989 \text { e } 30 \% \text { até } 2000 \text {. } \\
\text { 5) Valores a preços maio } / 87 \text { - Deflator: IGP } \\
\text { 6) Valores em CZ } \$ \text { mil }\end{array}$} \\
\hline
\end{tabular}

Elaboraçāo: Pedro Luiz Barros Sllva e André Medici

O terceiro cenário, otimista, supõe um crescimento da arrecadação da ordem de $2 \%$ entre 1987 e 1988 e $4,8 \%$ anuais entre 1989 e 2000 . Neste cenário, a economia brasi. leira poderia retomar, em moldes mais contidos, seu ritmo histórico de crescimento do produto e da renda permitindo absorver boa parte da população economicamente ativa, ele. var salários em termos reais e manter o desemprego a niveis próximos do friccional. As mesmas hipóteses para receita e participação do INAMPS seguem mantidas. Neste caso a elevação real bruta dos gastos do INAMPS, chegam a 
$111,5 \%$, garantindo recursos adicionais para o investimento e o custeio da política traçada para o setor saúde.

\section{Cenários Alternativos de Crescimento do Gasto do SINPAS}

Cenário Otimista

\begin{tabular}{|c|c|c|c|}
\hline Ano & $\begin{array}{l}\text { Arrecadação } \\
\text { Contribuição } \\
\text { Compulsória }\end{array}$ & $\begin{array}{c}\text { Receita } \\
\text { Total } \\
\text { SINPAS }\end{array}$ & $\begin{array}{l}\text { Despesa } \\
\text { Ass. Médica } \\
\text { INAMPS }\end{array}$ \\
\hline 1983 & 405.935 .495 & 432.566 .675 & 96.423 .036 \\
\hline 1984 & 354.134 .341 & 403.994 .193 & 102.681 .330 \\
\hline 1985 & 398.858 .619 & 439.420 .940 & 113.224 .675 \\
\hline 1986 & 491.956 .373 & 509.642 .530 & 120.097 .965 \\
\hline 1987 & 487.649 .297 & 555.600 .000 & 130.141 .494 \\
\hline 1988 & 497.402 .283 & 522.272 .397 & 141.013 .547 \\
\hline 1989 & 521.277 .592 & 547.341 .472 & 153.255 .612 \\
\hline 1990 & 546.298 .917 & 573.613 .863 & 172.084 .159 \\
\hline 1991 & 572.521 .265 & 601.147 .328 & 180.344 .198 \\
\hline 1992 & 600.002 .286 & 630.002 .400 & 189.000 .720 \\
\hline 1993 & 628.802 .395 & 660.242 .515 & 198.072 .755 \\
\hline 1994 & 658.984 .910 & 691.934 .156 & 207.580 .247 \\
\hline 1995 & 690.616 .186 & 725.146 .995 & 217.544 .099 \\
\hline 1996 & 723.765 .763 & 759.954 .051 & 227.986 .215 \\
\hline 1997 & 758.506 .520 & 796.431 .846 & 238.929 .554 \\
\hline 1998 & 794.914 .833 & 834.660 .574 & 250.398 .172 \\
\hline 1999 & 833.070 .744 & 874.724 .282 & 262.417 .285 \\
\hline 2000 & 873.058 .140 & 916.711 .047 & 275.013 .314 \\
\hline & \multicolumn{3}{|c|}{$\begin{array}{l}\text { 1) Crescimento arrecadaçäo } 87-88=-2 \% \\
\text { 2) Crescimento arrecadaçäo } 1988-2000=4,8 \% \\
\text { 3) Receita total } 5 \% \text { maior que a arrecadada } \\
\text { 4) Despesa do INAMPS equivalente a } 27 \% \text { receita em } \\
198828 \% \text { em } 1989 \text { e } 30 \% \text { até } 2000 \text {. } \\
\text { 5) Valores a preços maio } / 87 \text { - Deflator:IGP } \\
\text { 6) Valores em C2 \$ mil } \\
\text { NTESE DATAPREV }\end{array}$} \\
\hline
\end{tabular}

\section{Elaboração: Rdro Luiz Barros Sllva e André Medici}

A hipótese otimista nos favorece o manejo de projeção de alguns agregados macroeconômicos como o PIB. Supondo-se um crescimento anual real deste agregado na ordem de $2 \%$ de 1987 a 1990 (período de ajuste) e de $4 \%$ a partir de 1991 até o ano 2000, conforme tabela 8 , o PIB poderá chegar a 15,2 trilhões de cruzados no ano 2000 (57\% com relação a 1987). As despesas do INAMPS chegarão, conforme o cenário otimista, a $1,8 \%$ do PIB, o que representa $50 \%$ de aumento com relação ao gasto atual/PIB. 
TABELA 8

Projeção de Crescimento do PIB

\begin{tabular}{lc}
\hline & $\begin{array}{c}\text { PIB } \\
\text { CzS Bilhão }\end{array}$ \\
\hline 1980 & 8.601 \\
1981 & 8.021 \\
1982 & 7.987 \\
1983 & 7.703 \\
1984 & 7.887 \\
1985 & 8.781 \\
1986 & 9.506 \\
1987 & 9.696 \\
1988 & 9.890 \\
1989 & 10.088 \\
1990 & 10.290 \\
1991 & 10.701 \\
1992 & 11.129 \\
1993 & 11.574 \\
1994 & 12.037 \\
1995 & 12.519 \\
1996 & .13 .020 \\
1997 & 13.540 \\
1998 & 14.082 \\
1999 & 14.645 \\
2000 & 15.231 \\
\hline 089 & \\
\hline
\end{tabular}

OBS:

1) Preços maio/87

2) Crescimento anual entre 1987 e 1990 de $2 \%$ reais

3) Crescimento anual entre 1991 e 2000 de $4 \%$ reais

Fonte: Conjuntura Econômica

Elaboração: Pedro Luiz B. Silva e André Medici

Mantendo-se constante o gasto privado/PIB e almejando uma relação gasto total com saúde/PIB da ordem de $6,5 \%$, que é o padrão mínimo de gasto em um país com nível de desenvolvimento econômico equivalente a patamares de desenvolvimento social muito superiores, como a Argentina, chegamos a 990 bilhões de cruzados de gasto total em saúde, no ano 2000. A composição ótima desse gasto, expressa na tabela 9 seria de 213,2 bilhōes de gastos privados; 275 bilhões, como já foi visto, de contribuição da Previdência Social para a saúde; 379,8 bilhões das esferas descentralizadas de Governo e 122,0 bilhōes para a esfera federal. 
Com isso estamos supondo que a participação do gasto federal orçamentário em saúde em relação ao PIB deve ser multiplicada por dois e as dos Estados e Municípios por três. Note-se que, com isso, os recursos do orçamento fiscal contribuirão em igual medida com o esforço de gasto realizado na esfera privada e arrecadação através de contribuições compulsórias, o que nos parece razoável como meta factível num país com padrão de financiamento do gasto social tão pouco avançado.

Finalizando vale ressaltar, que somente a partir desse momento a política de atenção à saúde, enquanto uma ação governamental de caráter equânime e universal, estará sendo financiada majoritariamente pelos recursos oriundos, da tributação ordinária; meta almejada por todos aqueles que desejam ver estabelecida no Brasil uma cidade social plena.

TABELA 9

Composição Ótima dos Gastos em Saúde por Fontes de Recursos

Para se Chegar a 6,5\% do PIB no Ano 2000

Em Cz\$ bilhões de maio de 1987

\begin{tabular}{|c|c|c|c|c|c|c|c|c|}
\hline \multirow{3}{*}{$\begin{array}{l}\text { Niveis } \\
\text { Situacionais }\end{array}$} & \multirow[b]{3}{*}{ ABS } & \multirow{3}{*}{$\begin{array}{l}\text { Privado } \\
\% \text { do } \\
\text { PIB }\end{array}$} & \multicolumn{4}{|c|}{ Estrutura do Gasto } & \multirow{2}{*}{\multicolumn{2}{|c|}{ Orç. Federal }} \\
\hline & & & \multicolumn{2}{|c|}{ Previdenc. } & \multicolumn{2}{|c|}{ Est./Mun. } & & \\
\hline & & & ABS & $\begin{array}{c}\% \text { do } \\
\text { PIB }\end{array}$ & ABS & $\begin{array}{c}\% \text { do } \\
\text { PIB }\end{array}$ & ABS & $\begin{array}{l}\% \text { do } \\
\text { PIB }\end{array}$ \\
\hline $\begin{array}{l}\text { Atual 3,9\% } \\
\text { do PIB } \\
(1986)\end{array}$ & 130,0 & 1,4 & 113,8 & 1,3 & 65,0 & 0,8 & 34,4 & 0,4 \\
\hline $\begin{array}{l}\text { Prospectivo } \\
6.5 \% \text { do PIB } \\
(2000)\end{array}$ & 213,2 & 1,4 & 275,0 & 1,8 & 379,8 & 2,5 & 122,0 & 0,8 \\
\hline
\end{tabular}

Elaboração: Pedro Luiz Barros Silva e André Medici

Deflator: $I G P / D I$ 